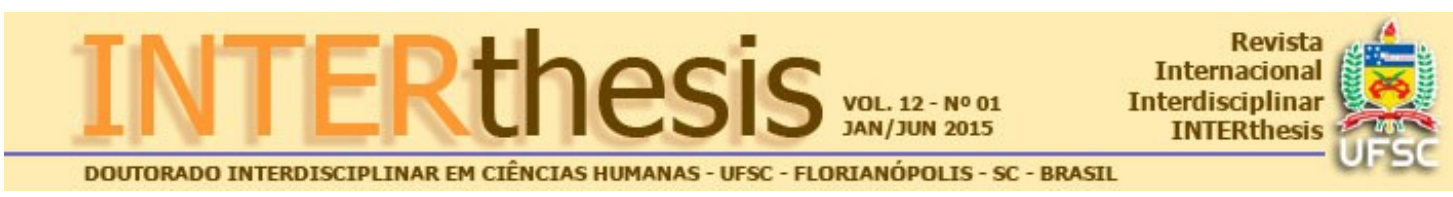

\title{
SOBRE O OLHAR ANTROPOCÊNTRICO: O SER HUMANO E O JARDIM ZOOLÓGICO
}

\author{
Rafael Speck de Souza ${ }^{1}$ \\ Letícia Albuquerque ${ }^{2}$
}

\section{Resumo:}

O presente artigo pretende questionar a primazia do humano e sua dominação sobre a natureza, a partir de uma crítica à obsolescência dos jardins zoológicos como reforçadores das fronteiras entre o humano e o animal. Para tanto, far-se-á uma análise do postulado antropocêntrico e da natureza dos zoológicos como espaços de marginalização forçada e confinamento animal. Para a obtenção dos objetivos colimados utilizar-se-á o método histórico, dedutivo e explicativo. Serão utilizados como fontes de pesquisa, eminentemente bibliográfica, livros, artigos e periódicos, tanto no meio eletrônico como impresso. Adotar-se-á como referenciais teóricos a Teoria dos Direitos Animais de Tom Regan e a Ética Animalista de Sônia T. Felipe, com o intuito de demonstrar a mais consentânea "saída" para esses e tantos outros casos de exploração: as jaulas vazias e a libertação animal.

Palavras-chave: Antropocentrismo. Jardim Zoológico. Habeas Corpus. Ética Animal. Direitos Animais.

\section{INTRODUÇÃO}

O presente artigo pretende analisar o antropocentrismo a partir de um olhar crítico sobre os jardins zoológicos, ambientes estes cuja lógica tradicionalmente mantém-se na dominação humana sobre os animais.

Muito se argumenta no sentido de que os jardins zoológicos cumprem uma função socioeducativa, de que ensinam crianças a estreitar os laços entre humanos e animais. Este artigo pretende contrapor essa ideia ao demonstrar que os zoológicos transmitem um contra-exemplo, qual seja, de que é admissível capturar

\footnotetext{
${ }_{1}^{1}$ Mestrando em Direito, Estado e Sociedade, Linha de Pesquisa "Direito, Meio Ambiente e Ecologia Política", pela Universidade Federal de Santa Catarina. Integrante do Observatório de Justiça Ecológica, grupo de pesquisa certificado pelo CNPQ. E-mail: rafaelspk@gmail.com.

2 Doutora em Direito pelo Programa de Pós-Graduação em Direito da Universidade Federal de Santa Catarina, com estágio de Doutoramento na Faculdade de Direito de Coimbra/Portugal, bolsista CAPES. Pesquisadora do Observatório de Justiça Ecológica, grupo de pesquisa certificado pelo CNPQ. Professora nos cursos de Graduação e Pós-graduação em Direito da Universidade Federal de Santa Catarina, Florianópolis, SC, Brasil. E-mail: leticia.albuquerque@ufsc.br
}

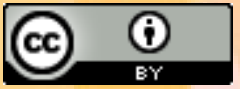


um animal na natureza e mantê-lo em cativeiro para o mero deleite de humanos que os visitam ocasionalmente. No âmago da questão, estaria o antropocentrismo, a reforçar a ideia de que os animais são inferiores e destituídos de um valor intrínseco.

$\mathrm{O}$ artigo pretende demonstrar que é indispensável uma mudança de olhar (paradigma) para bases mais respeitosas e moralmente justas. Conforme se abordará, será necessário repensar a forma como olhamos os animais, admitir que eles não são apenas "objeto" de nosso olhar, mas que também nos olham e possuem interesses que necessitam ser atendidos.

$\mathrm{Na}$ primeira seção, abordar-se-á os fundamentos do paradigma antropocêntrico em contraposição aos novos saberes e práticas culturais que expandem, para além das fronteiras do humano, o respeito e a consideração moral também aos animais não humanos. Para isso, partir-se-á do seguinte questionamento paradigmático: "Por que olhar os animais?".

$\mathrm{Na}$ segunda seção, será utilizado como ponto de referência para o debate a triste realidade dos jardins zoológicos e seu papel como difusores da marginalização forçada e do confinamento animal. Nesse sentido, serão apresentados dois casos: a chimpanzé Suíça e o urso polar Arturo.

$\mathrm{Na}$ terceira e última seção, apresentar-se-á os argumentos do que se entende como a mais consentânea "saída" para esses e tantos outros casos: as jaulas vazias e a libertação animal.

Como referenciais teóricos, serão utilizados a Teoria dos Direitos Animais de Tom Regan e a Ética Animalista de Sônia T. Felipe. Para a obtenção dos objetivos colimados utilizar-se-á o método histórico, dedutivo e explicativo. Serão utilizados como fontes de pesquisa, eminentemente bibliográfica, livros, artigos e periódicos, tanto no meio eletrônico como impresso.

\section{ANTROPOCENTRISMO}

Do grego "anthropos", homem, e do latim "centrum", centro, antropocentrismo é o paradigma que situa e explica o ser humano como o centro do universo e, ao mesmo tempo, como o fim segundo o qual tudo o mais deve estar ordenado e a ele subordinado (JAPIASSÚ; MARCONDES, 2008). Célebre citação que bem define o 
ser humano como medida autorreferente encontra-se em Protágoras de Abdera (490-420 a.C): "O homem é a medida de todas as coisas".

Todavia, esse modo de enxergar o mundo não representa um dado natural. Ao revés, ele advém de um constructo histórico-cultural que entendeu por separar "artificialmente" o ser humano da natureza. Além disso, tal visão antropocentrada subjugou todas as demais espécies à dominação humana.

Uma das pontas do enraizamento do antropocentrismo, sobretudo no mundo ocidental, encontra-se na religião. Eis um trecho bíblico exemplificativo: "Frutificai e multiplicai-vos, e enchei a terra, e sujeitai-a; e dominai sobre os peixes do mar e sobre as aves dos céus, e sobre todo o animal que se move sobre a terra" (Gênesis $1: 28)$.

Tal forma de olhar a natureza e os animais vem, pouco a pouco, sendo contestada e desafiada por outras abordagens e paradigmas, novos saberes e práticas culturais.

No viés arejado da "ética senciocêntrica", os animais são seres que nascem livres e são sencientes (sentem dor e prazer). Sua condição de "indivíduos" se mantém por autoprovimento. Em outras palavras, ao ser dotado da liberdade de "mover-se para prover-se", todo animal é constituído de uma forma específica de "senciência" (sensibilidade e/ou consciência) sem a qual não poderia gravar nem articular os conceitos necessários à manutenção de sua vida e à prevenção contra os riscos e ameaças do ambiente. Por isso, acorrentar, aprisionar e manter confinados os animais representa para eles um dos piores tormentos, pois ao nascerem foram separados da fonte de provimento, representada por suas progenitoras. Isso vale para qualquer espécie animal. Humanos demoram décadas para aprender as complexas interações requeridas para garantir o movimento para o autoprovimento. Animais têm um tempo mais curto para configurarem sua mente senciente (FELIPE, 2009, p. 12-14).

\section{JARDIM ZOOLÓGICO: ILOGICIDADE QUE SE PERPETUA}

A ideia do jardim zoológico surgiu na Inglaterra, no início do século passado, para exibir seres humanos, especialmente aqueles com deficiência e os de origem diferente. Para os conceitos da época era também comum e aceitável as visitas a 
manicômios como forma de diversão. Rapidamente, os humanos perceberam que esse tipo de exposição era uma afronta contra a própria espécie, não sendo apropriado exibir suas deformidades e atrasos, e com o tempo os animais substituíram os humanos (CAPUANO, 2014).

A grande maioria dos zoológicos, hoje, tem péssimas instalações e coloca os animais em situações constantes de estresse e sofrimento.

No Brasil, há 110 zoológicos e 13 aquários. Desses, 31 são particulares, 69 municipais, 04 estaduais, 02 do exército e os demais 17 são fundações ou administrações mistas. No Estado de São Paulo são 60 empreendimentos, a maior parte dos quais se encontra denunciado (GREIF, 2014).

O crítico de arte e historiador John Berger, em seu livro "Sobre o olhar", desafia-nos com o seguinte questionamento "Por que olhar os animais?"

Ele ressalta:

\begin{abstract}
Um zoológico é um lugar onde se coleciona a maior quantidade possível de espécies e variedades animais para serem vistas, observadas, estudadas. Em princípio cada jaula é uma moldura em torno do animal que está dentro dela. Os visitantes vêm ao zoológico para olhar os animais. Passam de jaula em jaula como visitantes de uma galeria de arte param na frente de um quadro, depois de outro e outro. Mas no zoológico a visão é sempre errada. Como uma imagem fora de foco. A gente fica tão acostumado a isso que quase nem nota mais; ou melhor, a apologia habitualmente antecipa a decepção, de modo que nem se sente esta última. $E$ a apologia é mais ou menos assim: O que é que você esperava? Você não veio olhar um objeto morto, ele está vivo. Leva a sua própria vida. Por que isso haveria de coincidir com ser adequadamente visível? Mas o raciocínio dessa apologia é inadequado. A verdade é mais espantosa. [...]. Seja como for que se contemplem esses animais, mesmo se o animal se ergue contra as grades a menos de meio metro de nós, olhando para fora, para o público, estaremos olhando algo que se tornou absolutamente marginalizado; e toda a concentração que possamos exercer jamais será suficiente para torná-lo central. Por quê? (BERGER, 2003, p. 29).
\end{abstract}

Conforme já dito, uma vez aprisionados e confinados, os animais não humanos (e isso se aplica aos humanos também) são destituídos do senso de provimento que lhes é próprio, restando privados da liberdade de buscar seu "próprio bem" a "seu próprio modo". A perda da liberdade, para um animal, ameaça sua consciência específica. O confinamento de animais os força a viverem a vida contrariando sua autonomia prática natural, pois os priva do bem próprio da espécie singular de seu viver. O "bem próprio a cada espécie" não pode ser oferecido por ninguém ao animal (FELIPE, 2009, p. 12). 
Os animais isolados uns dos outros e sem interação entre as espécies tornam-se totalmente dependentes de seus tratadores. Consequentemente, a maioria de suas reações muda. O que era central em seu interesse foi substituído por uma espera passiva de uma série de intervenções externas arbitrárias. Os fatos que percebem ao seu redor tornaram-se tão ilusórios em termos de suas reações naturais quanto os prados pintados. Ao mesmo tempo, esse mesmo isolamento garante a sua longevidade enquanto espécies, e facilita seu arranjo taxonômico (BERGER, 2003, p. 31).

Manter o animal não humano em cativeiro e preservar-lhe a integridade de seu espírito específico são coisas, a rigor, irreconciliáveis. Nesse aspecto, preleciona Sônia T. Felipe:

\begin{abstract}
O que os zoos fazem é procurar a reprodução biológica de espécies ameaçadas de extinção. Mas, quando falamos em preservar espécies não pensamos que uma espécie seja constituída apenas por sua bagagem genética. Cada espécie animal precisa de um espírito específico, que permita a preservação daquele tipo de vida de forma autônoma. Isso os zoos não podem fazer. No máximo, o que eles preservam, é o banco genético. Ao serem mantidos no cativeiro por tempo muito longo, refiro-me aos indivíduos da primeira geração posta em confinamento, os animais apagam pouco a pouco a memória que constituía seu "espírito" específico. Se duas ou três gerações são mantidas nesse cativeiro, não resta conhecimento algum que permita aos jovens nascidos em confinamento saber interagir no espaço natural e social que seria próprio de sua espécie de vida. Guardamos, assim, o patrimônio genético, que é matéria biológica. Matamos o patrimônio genuinamente "animal" dessas espécies. Temos apenas "organismos" destituídos de "mente" específica. Por esse motivo, reproduzir animais em zoos não garante que sua espécie de vida seja preservada. Insisto: manter um corpo funcionando não é tudo quando se trata da riqueza espiritual que cada espécie viva representa (FELIPE, 2014).
\end{abstract}

Feito esse intróito, retome-se o inquietante questionamento "Por que olhar os animais?"

Berger (2003, p. 22) conduz o raciocínio ao fato de que "os animais são sempre os observados". O fato de que eles podem nos observar perdeu todo o significado. Eles são os objetos de nosso conhecimento sempre crescente. O que sabemos sobre eles é um índice de nosso poder, e assim é um índice do que nos separa deles. Quanto mais sabemos, mais distantes eles ficam.

O filósofo franco-argelino Jacques Derrida objetivando colocar em questão a relação humano-animal que domina o pensamento ocidental durante séculos, relata o incômodo gerado do encontro dele próprio com sua gata que the olhava nu. A propósito, extrai-se da obra L'animal que donc je suis ("O animal que logo sou”): 
Frequentemente me pergunto, para ver, quem sou eu - e quem sou eu no momento em que, surpreendido nu, em silêncio, pelo olhar de um animal, por exemplo os olhos de um gato, tenho dificuldade, sim, dificuldade de vencer um incômodo. [...]. E a partir desses estar-aí-diante-de-mim, ele pode se deixar olhar, sem dúvida, mas também, a filosofia, talvez o esqueça, ele seria mesmo esse esquecimento calculado, ele pode, ele olhar-me. Ele tem seu ponto de vista sobre mim. O ponto de vista do outro absoluto, e nada me terá feito pensar tanto sobre essa alteridade absoluta do vizinho ou do próximo quanto os momentos em que eu me vejo visto nu sob o olhar de um gato (DERRIDA, 2002, p. 15 e 28).

Segundo Derrida, faz-se necessário que se reconsidere a maneira como se trata os animais e também as teorias sobre animalidade. Para tanto, ele propõe: a) o repensar sobre a interação humano-animal (a relação com o indivíduo animal); b) a reflexão sobre "quem sou eu" (uma questão eminentemente "autobiográfica").

Paixão (2013, p. 274) esclarece que Derrida propõe um arranjo de abordagens sobre animalidade dividindo-as em dois grandes grupos: o primeiro grupo compreende "os textos assinados por pessoas que sem dúvida viram, observaram, analisaram, refletiram o animal, mas nunca se viram vistas pelo animal", enquanto o outro grupo "são antes de mais nada poetas ou profetas, em situação de poesia ou de profecia, do lado daqueles e daquelas que confessam tomar para si a destinação que o animal lhes endereça, antes mesmo de terem o tempo e a possibilidade de se esquivar nus ou em roupão" (DERRIDA, 2002, p. 32 e 34).

$\mathrm{Na}$ forma de tratar/olhar o animal não humano, vale lembrar a importante lição de Tom Regan, em seu livro "Jaulas Vazias", quando evidencia que a relação humano-animal pode se dar segundo a perspectiva "eu-tu" ou "eu-isso". Na primeira forma, vê-se o animal como "sujeito-de-uma-vida" (dotado de valor intrínseco), ao passo que da segunda forma vigora o paradigma da "coisificação animal" (dotado de mero valor instrumental).

\section{O CASO SUÍÇA: A VIA DO HABEAS CORPUS}

Suíça era um chimpanzé que se encontrava aprisionada no Jardim Zoológico de Salvador/BA, em uma jaula com área total de $77,56 \mathrm{~m} 2$, altura de 4,0 metros de solário e área de confinamento de 2,75 metros de altura, impedida, portanto, de seu direito de locomoção. "Suíça" vivia sozinha desde que seu companheiro de jaula "Geron" morrera de câncer, em 20.04.2005.

R. Inter. Interdisc. INTERthesis, Florianópolis, v.12, n.1, p.117-129, Jan-Jun. 2015 
Em 19.09.2005, um grupo de professores, estudantes e ativistas de Direitos dos Animais do Estado da Bahia, capitaneado pelo Promotor de Justiça Heron José de Santana Gordilho, impetrou, de modo pioneiro, uma ação de Habeas Corpus em favor de Suíça.

Infelizmente, em 27.09.2005, a chimpanzé Suíça veio a óbito e o processo fora extinto sem julgamento de mérito. Com a morte da paciente do $\mathrm{HC}$ deu-se a perda do objeto da ação (qual seja, a coação ilegal do direito de locomoção de Suíça).

Não obstante a extinção de referido Habeas Corpus, impende observar que o juiz daquela demanda admitira Suíça como sujeito de direito, conforme ressaltou o professor Heron Gordilho:

Em sentença publicada no Diário do Poder Judiciário de 5 de outubro de 2005 (data comemorada como o dia mundial dos animais), o Juiz Edmundo Lúcio da Cruz, da $9^{a}$ Vara Criminal do Tribunal de Justiça do Estado da Bahia, julgou o Habeas Corpus n. 833085-3/2005, abrindo um precedente histórico para o mundo jurídico, ao admitir que uma chimpanzé como sujeito de direito em uma demanda judicial (GORDILHO, 2008, p. 1593).

O caso Suíça vs. Zoológico de Salvador/BA tornou-se um marco histórico no Direito brasileiro, com repercussão internacional.

Acerca da utilização de Habeas Corpus em favor de grandes primatas, vale pontuar a recente decisão americana de 20.4.2015, em que a ministra do Tribunal Superior de Nova York Barbara Jaffe concedera liminar em HC impetrado pela ONG The Nonhuman Rights Project, em favor dos chimpanzés Hercules e Leo, garantindo-lhes a libertação do laboratório da Universidade Stony Brook, onde viviam confinados. Referida ação ainda aguarda julgamento de mérito a fim de se reconhecer ou não, o status de pessoa dos chimpanzés.

\section{O CASO ARTURO: O URSO MAIS TRISTE DO MUNDO}

A situação do urso polar "Arturo" tem comovido diversos ativistas pelo mundo (as imagens na internet falam por si). Arturo nasceu nos Estados Unidos, mas vive confinado em um zoológico em Mendoza, na Argentina, há duas décadas. Em 2012, ele perdeu sua parceira "Pelusa" e entrou em depressão. Até hoje, Arturo vive em condições insalubres para sua espécie e precisa suportar temperaturas muito 
quentes, ao ponto de partes de seu pelo chegarem a apresentar queimaduras provocadas pelo Sol.

Apesar de uma petição assinada por mais de meio milhão de pessoas que reclamava a mudança de Arturo para o Canadá (cujo clima é mais próximo ao de seu habitat), o diretor do zoológico de Mendoza afirmou que o urso de 28 anos e em fim de vida, está numa idade demasiado avançada para ser realocado.

Eis relato do estado mental de Arturo, em julho de 2014:

\begin{abstract}
A professora argentina Fernanda Arentsen, que leciona na Universidade de Saint-Boniface em Winnipeg, escreveu ao governo de seu país e à embaixada canadense em Buenos Aires a respeito de Arturo. Ela disse ao Winnipeg Free Press no ano passado: "Você pode ver que ele está enlouquecendo. Ele se move do jeito que ursos polares fazem quando estão sofrendo demasiado estresse. Ele parece tão triste. Ele aparenta estar em pânico. Imagine um urso polar no deserto, com uma piscina de $50 \mathrm{~cm}$ de profundidade. É difícil olhar esse animal sofrendo e em desespero", conta a professora, que diz que nasceu em Mendoza e conhece a alta temperatura do local. ${ }^{3}$
\end{abstract}

A ONG argentina AFADA (Associação dos Funcionários e Advogados pelos Direitos dos Animais) chegou a impetrar uma ação de Habeas Corpus em favor de Arturo, todavia, em 10.02.2014, o pedido foi rejeitado pelo Tribunal de Garantias n. 5 , da cidade de Mendoza, ao argumento de aos animais falta-lhes personalidade. $O$ juiz do processo teve a possibilidade de mudar o rumo da história no país vizinho, mas optou por manter o "status quo".

\title{
6 “- ONDE FICA A SAÍDA?”
}

O ser humano inventa desculpas para justificar (tornar justo) suas más ações. Isso cria uma sensação de conforto, ainda que as desculpas sejam pouco convincentes. É fácil verificar que um zoológico não pode ser justificado pelo ponto de vista ético: o que justificaria manter animais selvagens em gaiolas e jaulas? (GREIF, 2014).

Muitos seres humanos justificam que os zoológicos apresentam função socioeducativa ("conhecer para preservar"), contudo, como adverte o biólogo Sérgio Greif:

3 Disponível em: http://www.anda.jor.br/16/07/2014/urso-polar-arturo-continua-confinado-argentinaenlouquecendo. Acesso em: 19 set. 2014.

R. Inter. Interdisc. INTERthesis, Florianópolis, v.12, n.1, p.117-129, Jan-Jun. 2015 
Uma criança que vê um elefante em um recinto de fato aprecia o animal, mas a mensagem que ela recebe, ainda que de maneira subliminar, é a de que podemos aprisionar animais. Animais são inferiores e nós somos superiores. E nossa superioridade nos permite capturar um animal na natureza e mantê-lo em cativeiro. Criamos a simpatia pelo animal, mas à medida que o animal se assemelha a nós mesmos (GREIF, 2014).

Nada aprendemos sobre a natureza de um animal quando o vemos por detrás de grades de ferro, isolado, infeliz e distante do ambiente que seria próprio ao seu caráter (FELIPE, 2013).

Algumas alternativas poderiam ser implementadas no lugar dos zoológicos: a) utilização de documentários e filmes em 3D como substitutivos à visitação de tais espaços de confinamento; b) uso de robôs e hologramas para se "materializar" animais e suas interações fidedignas ao habitat; c) repatriar os animais silvestres ao seu habitat, quando possível; d) encaminhar os animais "domesticados" para santuários ecológicos.

Sobre uma possível destinação aos zoológicos, adverte Felipe (2013):

\begin{abstract}
Os zoos só fariam sentido, hoje, se transformados em hospitais de custódia para animais feridos ou ameaçados, que poderiam ser protegidos por tempo determinado, até que pudessem ser devolvidos ao seu ambiente natural. Mas, nesse caso, nenhum zoo deveria ser aberto à visitação pública, do mesmo modo que hospitais e unidades de tratamento intensivo humanos não são centros de exposição ou visitação públicas. Se temos curiosidade para saber como uma determinada espécie animal se move na natureza, melhor ver os filmes feitos por cientistas que abandonaram a vida nas cidades para dedicarem-se integralmente ao estudo da vida animal.
\end{abstract}

Todos os locais de marginalização forçada - guetos, favelas, prisões, hospícios, campos de concentração - têm algo em comum com zoológicos. Mas é fácil e evasivo demais usar o zoológico como símbolo. O zoológico é uma demonstração das relações entre homem e animais: nada mais que isso (BERGER, 2003, p. 32).

A solução ou saída para esse problema ético, como defende Tom Regan, são as "jaulas vazias", simples assim. Nada justifica a manutenção desta prática obsoleta de confinamento que subjuga animais de outras espécies, os marginaliza e os debilita mental e psicologicamente. 


\section{CONSIDERAÇÕES FINAIS}

Ante os fatos trazidos, pode-se concluir que os jardins zoológicos encontramse maculados desde o seu surgimento, quando se destinavam à exposição pública de animais humanos e, posteriormente, à exposição somente de animais não humanos enjaulados.

Como foi possível verificar, os zoológicos são espaços de confinamento nocivos aos animais e, simbolicamente, retratam as relações que, há muito tempo, veem sendo estabelecidas entre humanos "superiores" e os outros animais.

Nesse viés, a pretexto do que muitos alegam serem os "zoos" locais para se "conhecer os animais", verificou-se que tais prisões em que humanos visitam os animais são, na verdade, um monumento à impossibilidade de tais encontros.

Viu-se que nada se aprende sobre a verdadeira natureza de um animal quando o vemos enjaulado, infeliz e afastado do habitat próprio a sua espécie.

Por outro lado, para modificar o olhar arrogante e antropocêntrico será necessário o exercício de sair de si (sair do centro), ver-se no outro, ainda que este outro seja um animal que pertença à outra espécie.

Reconhecer que os animais não humanos são seres sencientes e que possuem uma mente específica que precisa ser preservada faz parte do genuíno processo de aprendizagem e de empatia calcados na Ética Animal, algo mais sério do que promover visitas a "coleções" de animais desfigurados em sua natureza e debilitados pela clausura e solidão. 


\title{
ON THE ANTHROPOCENTRIC VIEW: A MAN IN THE ZOO
}

\begin{abstract}
This paper intends to question the primacy of human beings and their domination over nature based on a critique of the obsolescence of zoos as reinforcers of boundaries between humans and animals. The analysis was conducted of the anthropocentric assumption and of the nature of zoos as places of forced marginalization and animal confinement. In order to achieve the established goals, the historical, deductive and explanatory method is applied. Books, papers and journals have been used as bibliographical sources. Tom Regan's Theory of Animal Rights and Sônia T. Felipe's Animal Ethics have been adopted to demonstrate the most adequate "solution" for these and so many other cases of animal exploration: empty cages and animal freedom.
\end{abstract}

Keywords: Anthropocentrism. Zoo. Habeas Corpus. Animal Ethics. Animal Rights.

\section{SOBRE LA MIRADA ANTROPOCÉNTRICA: UN HOMBRE EN EL JARDÍN ZOOLÓGICO}

\section{Resumen}

El presente artículo tiene el propósito de cuestionar la primacía del humano y su dominio sobre la naturaleza, a partir de una crítica a la obsolescencia de los jardines zoológicos como reforzadores de las fronteras entre el humano y el animal. Para eso, se realizó un análisis del postulado antropocéntrico y de la naturaleza de los zoológicos como espacios de marginalización forzada y confinamiento animal. Para lograr los objetivos trazados, se utilizó el método histórico, deductivo y explicativo. Se utilizaron como fuentes de investigación, eminentemente bibliográfica, libros, artículos y periódicos. Se adoptaron como referenciales teóricos la Teoría de los Derechos Animales de Tom Regan y la Ética Animalista de Sônia T. Felipe, con el objetivo de demostrar la más congruente "salida" para esos y tantos otros casos de explotación: las jaulas vacías y la liberación animal.

Palabras claves: Antropocentrismo. Jardín Zoológico. Habeas Corpus. Ética Animal. Derechos Animales. 


\section{REFERÊNCIAS}

BERGER, John. Sobre o olhar. Trad. Lya Luft. Barcelona: Gustavo Gili, 2003.

CAPUANO, Ricardo Luiz. Zoológicos e animais. Disponível em:

http://www.anda.jor.br/27/08/2014/zoologicos-animais. Acesso em: 19 set. 2014.

Chimpanzé morre antes que Justiça decida sobre habeas corpus na BA. Folha de São Paulo, 27 set. 2005. Disponível em:

http://www1.folha.uol.com.br/folha/cotidiano/ult95u113510.shtml. Acesso em 18 set. 2014.

DERRIDA, Jacques. $\mathbf{O}$ animal que logo sou. Trad. Fábio Landa. São Paulo: UNESP, 2002.

Entrevista completa com Sônia T. Felipe. Portal Terra. Disponível em: http://www.terra.com.br/noticias/ciencia/infograficos/zoos/zoos-02.htm. Acesso em: 18 set. 2014.

FELIPE, Sônia T. Antropocentrismo, senciocentrismo e biocentrismo: perspectivas ética abolicionistas, bem-estaristas e conservadoras e o estatuto de animais não-humanos. Disponível em:

https://www.metodista.br/revistas/revistasims/index.php/PF/article/viewFile/864/1168. Acesso em: 19 jun. 2015.

GREIF, Sérgio. Zoológicos. Disponível em: http://www.anda.jor.br/11/09/2014/zoologicos-3. Acesso em: 19 set. 2014. JAPIASSÚ, Hilton; MARCONDES, Danilo. Dicionário Básico de Filosofia. 5. ed. Rio de Janeiro: Zahar, 2008.

Justiça dos EUA reconhece status de pessoa a chimpanzés por um dia. Consultor Jurídico, 25 abr. 2015. Disponível em: http://consultorjuridico.jusbrasil.com.br/noticias/183650854/justica-dos-eua-reconhece-status-depessoa-a-chimpanzes-por-um-dia. Acesso em 27 abr. 2015.

ONG argentina apresenta Habeas Corpus a favor do urso polar Arturo. Agência de Notícias de Direitos Animais, 12 fev. 2014. Disponível em:

http://www.anda.jor.br/12/02/2014/ong-argentina-apresenta-habeas-corpus-favorurso-polar-arturo. Acesso em: 18 set. 2014. 
PAIXÃO, Rita Leal. Sob o olhar do outro. Derrida e o discurso da ética animal. Disponível em:

http://periodicos.pucminas.br/index.php/SapereAude/article/view/5507/5490. Acesso em: 18 set. 2014.

REGAN, Tom. Jaulas vazias: encarando o desafio dos direitos animais. Trad. Regina Rheda; Rev. Sônia Felipe e Rita Paixão. Porto Alegre: Lugano. 2006.

The man who was caged in a zoo. The Guardian, 3 jun. 2015. Disponível em: http://www.theguardian.com/world/2015/jun/03/the-man-who-was-caged-in-azoo?CMP=fb gu. Acesso em 13 jun. 2015.

Urso polar Arturo continua confinado na Argentina e está enlouquecendo. Agência de Notícias de Direitos Animais, 16 jul. 2014. Disponível em:

http://www.anda.jor.br/16/07/2014/urso-polar-arturo-continua-confinado-argentinaenlouquecendo. Acesso em: 18 set. 2014.

Artigo:

Submetido em 05.05.2015

Aceito em 03.06.2015 